\title{
ICTs and the urban-rural divide: can online labour platforms bridge the gap?
}

\section{Fabian Braesemann, Vili Lehdonvirta \& Otto Kässi}

To cite this article: Fabian Braesemann, Vili Lehdonvirta \& Otto Kässi (2022) ICTs and the urbanrural divide: can online labour platforms bridge the gap?, Information, Communication \& Society, 25:1, 34-54, DOI: $10.1080 / 1369118 X .2020 .1761857$

To link to this article: https://doi.org/10.1080/1369118X.2020.1761857

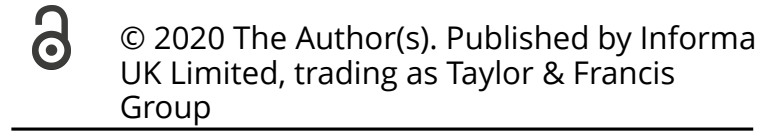
UK Limited, trading as Taylor \& Francis Group

曲 Published online: 06 May 2020.

Submit your article to this journal

Џlll Article views: 3580

Q View related articles

View Crossmark data $\nearrow$

Citing articles: 9 View citing articles $\sqsubset$ 


\title{
ICTs and the urban-rural divide: can online labour platforms bridge the gap?
}

\author{
Fabian Braesemann (D), Vili Lehdonvirta (1) and Otto Kässi (D)* \\ Oxford Internet Institute, University of Oxford, Oxford, UK
}

\begin{abstract}
Information and communication technologies have long been predicted to spread economic opportunities to rural areas. However, the actual trend in the 21st century has been the opposite. Knowledge spillovers have fuelled urbanisation and pulled job-seekers into large cities, increasing the gap with rural areas. We argue that new assemblages of technologies and social practices, so-called 'online labour platforms', have recently started to counter this trend. By providing effective formal and informal mechanisms of enforcing cooperation, these platforms for projectbased remote knowledge work enable users to hire and find work across distance. In analysing data from a leading online labour platform in more than 3000 urban and rural counties in the United States, we find that rural workers made disproportionate use of the online labour market. Rural counties also supplied, on average, higher-skilled online work than urban areas did. However, many of the most remote regions of the country did not participate in the online labour market at all. Our findings highlight the potentials and limitations of such platforms for regional economic development.

CODE AND DATA: www.github.com/Braesemann/Rural
\end{abstract}

\section{ARTICLE HISTORY}

Received 21 December 2018

Accepted 16 April 2020

\section{KEYWORDS}

Information and

communication technology; platform economy; online labour platforms; urban-rural divide; Social data science; regional development

\section{Introduction}

Digital technologies have enabled new online marketplaces, created new industries, and started to fundamentally change many parts of the economy (Mayer-Schönberger \& Ramge, 2018). They have also fuelled urbanisation, as large metropolitan areas have emerged as clusters of knowledge-intensive industries, providing highly paid, creative jobs (Clark et al., 2018; Florida \& Mellander, 2018; Forman et al., 2018). These jobs have pulled educated workers into the large cities, sparking knowledge spillovers and further increasing the gap between thriving urban centres and rural areas. Despite early promises to the contrary, the Internet has so far failed to turn the world into a 'spaceless city' (Pawley, 1995).

CONTACT Fabian Braesemann fabian.braesemann@sbs.ox.ac.uk

*Etla Economic Research for the author Otto Kässi

This article has been republished with minor changes. These changes do not impact the academic content of the article.

(c) 2020 The Author(s). Published by Informa UK Limited, trading as Taylor \& Francis Group

This is an Open Access article distributed under the terms of the Creative Commons Attribution-NonCommercial-NoDerivatives License (http://creativecommons.org/licenses/by-nc-nd/4.0/), which permits non-commercial re-use, distribution, and reproduction in any medium, provided the original work is properly cited, and is not altered, transformed, or built upon in any way. 
However, new assemblages of technologies and social practices, so-called 'online labour platforms', have recently started to re-imagine the entire hiring and work process, by enabling workers and employers to conclude contracts and enforce cooperation across distance. The platforms are web-applications that mediate between buyers and sellers of remotely deliverable informational labour, such as software development, graphic design, and data entry (Horton, 2010). As their use is growing rapidly (Kässi \& Lehdonvirta, 2018b; Kuek et al., 2015; Manyika et al., 2015), we ask whether these platforms might finally alleviate the urban-rural divide and bring economic opportunities to the countryside.

Research on the geography of online labour markets has so far focussed on the country level (Horton et al., 2017; Kässi \& Lehdonvirta, 2018b), and on frictions affecting the international service trade on these platforms (Beerepoot \& Lambregts, 2015; Ghani et al., 2014; Hong \& Pavlou, 2014). Urban-rural differences in the use of online labour platforms remain poorly understood.

To address this gap, we examine sub-national differences in online labour supply between urban and rural areas, evaluating whether such platforms have helped rural workers to find work online. To achieve this, we match geocoded transactions data from a leading online labour platform with data from US county-level labour market statistics. ${ }^{1}$ The findings suggest that online labour platforms disproportionately benefit skilled workers in rural areas.

\section{Background: the tenacity of distance}

Short distances allow ideas to move easily, making cities hotbeds of innovation and business opportunities (Florida \& Mellander, 2018; Glaeser \& Kahn, 2004). But information and communication technologies (ICTs) have long been predicted to make cities as hubs of economic organisation obsolete (Cairncross, 1997; Gaspar \& Glaeser, 1998; Graham, 1998). This is because 'all persons tapped into the global communications network [...] have ties approximating those used in a given metropolitan region' (Webber, 1968, p. 1096). As a result, 'What once had to happen in the city can now take place anywhere' (Pascal, 1987, p. 602). This includes work and business: 'the Internet creates a "borderless" virtual business platform on which suppliers, customers, competitors and network partners can freely interact [and] by-pass the traditional interaction patterns' (Poon \& Jevons, 1997, p. 34). As ICTs proliferate, 'it is no longer necessary to leave your home to work' (Morgan \& Smit, 1996, p. 136).

These predictions presume that ICTs function as near-perfect substitutes to proximate interactions: that they provide 'all the richness and subtlety of the immersive communications once available only through place-based interactions in urban areas' (Graham, 1998, p. 169). The 'Information Superhighway' makes actual highways unnecessary (Sawhney, 1996) and turns the world into a 'global village' (McLuhan, 1964). Every area, no matter how rural, is integrated into a 'spaceless city' where 'the whole population might require no more than the 30 atom diameter light beam of an optical computer system' (Pawley, 1995). According to Graham (1998, p. 168), "the "logic" of telecommunications and electronic mediation is therefore interpreted as inevitably supporting geographical dispersal from large metropolitan regions, or even the effective dissolution of the city itself. 
The rising 'knowledge economy' discourse (Drucker, 1969) also helped to fuel these predictions. As knowledge processing contributed increasingly to the economic value produced by firms and countries, the relative economic importance of the manipulation and transportation of physical matter diminished. 'Informational labour' - the accumulation, manipulation, and dissemination of various forms of information - started to be seen as the most important segment of the labour market (Castells, 1998). Even if physical capital, labour, and products could never be carried by the Information Superhighway, the fruits of informational labour or 'knowledge work' could be transmitted with ease. The economy was increasingly made up of spaceless 'bits', rather than geographically bound 'atoms' (Negroponte, 1995).

Although ICTs have undeniably had a substantial effect on the organisation of economic activities, they have not made cities obsolete. Urbanisation remains a megatrend in the 21st century, and it has only accelerated in recent years (Clark et al., 2018; Glaeser et al., 2001). More than half the world's population now lives in cities, and this proportion will rise to more than two-thirds by 2050 (UN, 2018). In North America, already four out of five people live in urban areas. People flock to urban centres in search of jobs and other opportunities. But the phenomenon also has downsides, which are felt in both urban and rural areas. Urban areas have become more congested (Castells-Quintana, 2017) and housing prices in urban areas have risen disproportionally (Ganong \& Shoag, 2017; Glaeser \& Gyourko, 2018). At the same time, rural communities have fallen behind on many dimensions, such as income, wealth, and provision of public services (Glasmeier, 2018). Against the face of massive ICT adoption, the effects of distance thus remain surprisingly tenacious. To emulate Robert Solow, 'you can see the information age everywhere but on the map'.

What explains this 'urbanisation paradox'? A rich body of previous research has approached this question from the point of view of examining urban-rural differences in Internet availability, adoption, and use (Gilbert, 2010; Howard et al., 2010; Philip \& Williams, 2018; Salemink et al., 2017; Strover, 2014). It is beyond the scope of this article to offer a comprehensive review, but some main findings are as follows. The availability of broadband Internet in the United States only recently reached good coverage in rural areas (Horrigan, 2010), and rural areas still lag behind cities in broadband adoption (Riddlesden \& Singleton, 2014; Stern et al., 2009). Even when good Internet infrastructure is available and adopted, its usefulness to rural inhabitants is compromised by a lack of access to 'digital literacy' or 'Internet skills' (Hargittai, 2002; Strover, 2014). Thus, according to this reading of the 'digital divides' literature, place still matters: ICTs have not made cities obsolete, because their availability, adoption, and use remains unevenly distributed in a way that favours cities and disadvantages rural areas.

We take a somewhat different approach to the question. Even assuming that Internet adoption and use were even across geography and not affected by digital divides, would urbanisation be halted? The 'death of distance' (Cairncross, 1997) literature predicts that ICTs would eliminate the urban advantage by allowing information to flow anywhere with equal ease. However, we argue that information flows alone are not sufficient to trigger the spatial reorganisation of economic activities. Online job adverts replaced local newspaper advertisements, but hiring processes retained other location-specific parts, such as face-to-face interviews, reproducing the urban advantage. We argue that this is because markets require not only information, but also other kinds of support to function. 
Economic sociology and economic history emphasise that to function effectively, job markets and firms need 'systems of control': means of enforcing cooperation and combating opportunism (Granovetter, 2005; North, 1990; Ogilvie, 2011). Workers need to be reasonably sure that they will get paid, and employers need to be reasonably sure that they get the labour that they are paying for. Both can be secured either by formal mechanisms of monitoring and sanctioning, such as contracts and courts (North, 1990), or by embedding economic activities in informal social networks that provide trust and social control (Granovetter, 1985; Shevchuk \& Strebkov, 2018). Without any control mechanisms, economic activity is unlikely to arise at all.

Formal and informal control mechanisms are available in proximate transactions, but not necessarily in ICT-mediated transactions. If a distant client fails to pay, they may be difficult to take to court as they may be unidentifiable or belong to a different jurisdiction. Distant parties are also unlikely to belong to the same social networks and may adhere to different cultural norms, making informal enforcement of cooperation equally difficult. Consequently, although ICTs enhanced information flows and enabled telecommuting and virtual teamwork, this did not result in job vacancies being filled over distance. People still needed to move to cities to look for work. In line with this argument, research suggests that cities have benefited disproportionately more than rural areas from reduced communication and search costs associated with the Internet (Forman et al., 2018; Kok \& Weel, 2014), and that many digital platforms have reinforced the importance of spatial proximity and cities (Baker \& Ward, 2002; Davidson \& Poor, 2018; Mollick, 2014; Verboord \& Noord, 2016).

However, a new wave of technologies and digitally mediated social practices could finally be diminishing the urban advantage to some extent. So-called online labour platforms are web-applications that mediate between buyers and sellers of remotely deliverable informational labour, such as software development, graphic design, and data entry (Horton, 2010). A World Bank study estimates that such platforms had annual turnovers of $\$ 4.8$ billion in 2016, which may grow to $\$ 15-\$ 25$ billion by 2020 (Kuek et al., 2015). Although these figures remain small compared to overall labour markets, the market has grown approximately $26 \%$ over two years (Kässi \& Lehdonvirta, 2018b), which is a rapid growth rate for a labour market.

Besides allowing parties to find each other and communicate, online labour platforms provide multiple mechanisms for enforcing cooperation over distance, including reputation systems, escrow systems, remote monitoring, and online dispute resolution systems (Pallais, 2014; Pallais \& Sands, 2016; Pelletier \& Thomas, 2018; Wood, Graham, et al., 2018). ${ }^{2}$ Both workers and employers can perform 'due diligence' checks on each other based on platform-verified and platform-generated signals that are not merely a 'cheap talk' (Lehdonvirta et al., 2018). Many users also use associated online forums and networks to exchange information about bad actors and to promulgate informal norms of good conduct (Flecker, 2016; Hardy \& Hollinshead, 2016; Lehdonvirta, 2016; Shevchuk \& Strebkov, 2018; Wood, Lehdonvirta, et al., 2018). Although these new ICT-mediated systems of control are by no means perfect (Agrawal et al., 2016; Lehdonvirta et al., 2018) and continue to reproduce many biases and dysfunctions (Hannák et al., 2017; Wood, Graham, et al., 2018), they do seem powerful enough to make it possible for many people to hire and find work across vast geographic distances. 
Despite the potential implications of these non-proximate systems of control for urban-rural divides, previous research has not empirically investigated online labour platforms on the sub-national level. To our knowledge, only one study (Borchert et al., 2018) examines the effect of local economic factors on the economic geography of online labour markets. The purpose of this paper is therefore to examine whether online labour platforms have helped to finally deliver on ICTs' promise to alleviate the 'tyranny of distances' (Virilio, 1993, p. 10) in extending economic opportunities to rural areas (Manyika et al., 2015).

\section{Theory and hypotheses}

Based on the theoretical considerations about the relation between place and ICTs, we sketch out a simple theoretical model of the use of online labour platforms across the urban-rural divide, and derive two hypotheses from it. Our starting point is that urban areas offer more employment opportunities than rural areas, pulling job-seekers towards cities (Glasmeier, 2018; Greenwood, 1997; Lucas, 2004). Online labour platforms offer an alternative to such employment-based migration, constituting a form of 'virtual migration' (Ipeirotis \& Horton, 2011). Accordingly, rural workers should have more incentives to use these platforms to find work than individuals in urban areas, where employment opportunities are widespread. This is captured by our first hypothesis:

H1: Rural areas supply more online labour proportional to population than urban areas do.

However, cities do not only provide more employment opportunities: they also support more specialised jobs and greater occupational diversity, thanks to urban agglomeration (Bettencourt et al., 2014; Quigley, 1998; Sveikauskas, 1975). Specialisation generates productivity gains allowing skilled workers to command higher wages. In rural areas, however, employers are sparse, and there is less opportunity to specialise. Highly specialised workers will find it difficult to secure enough specialised work in their narrow domain. They will either have to look for more generalist, less well remunerated tasks or migrate to cities. If online labour platforms alleviate geographic constraints on job search, then this should disproportionately benefit rural specialists, as they can access specialised demand beyond their local areas, reaping the gains of 'virtual agglomeration'. Because urban areas also provide specialised education and training to more people than rural areas do, we also need to take the area's general educational level into account when comparing urban-rural differences in specialised online labour supply. ${ }^{3}$ Our second hypothesis is therefore:

H2: Rural areas supply higher-skilled online labour relative to their general education level than urban areas do.

\section{Data and methods}

To examine the hypotheses, we construct novel measures of skill-specific online labour supply in the United States. We provide descriptive and inferential statistics to compare online labour supply in urban and rural counties in the presence of socio-economic control variables. 


\subsection{Data sources}

Our main online labour dataset consists of all transactions carried out on a leading online labour platform between 1 March 2013 and 31 August 2013. It comprises 362,989 projects and includes each project's job category (34 possible categories) and the worker's location on a zip-code level. ${ }^{4}$

To ensure that the findings speak to urban-rural differences, we limit ourselves to projects where the workers are located in the United States. The analysis hinges on countyand occupation-level data available from the US Census Bureau and the Bureau of Labour Statistics. Sub-national and occupational data are available from statistical agencies in other countries as well, but their levels of aggregation vary, and cross-national comparability is not straightforward.

To aggregate the platform data to the county level used in official US statistics, we use the Google Geocoding API and polygonal shapefiles published by the US Census Bureau. ${ }^{5}$ Filtering leaves us with 34,198 projects in 3052 counties in the 48 contiguous US states.

We employ the US Office of Management and Budget classification system to operationalise the urban-rural distinction. It assigns each county into either a rural, micropolitan, or metropolitan area. The area classifications are based on population concentration rather than on population numbers, which is in line with economic theorising on geographic concentration. A metropolitan area is defined as a core urban agglomeration of 50,000 or more people, while a micropolitan area has an urban core of at least 10,000 people. All other areas are rural. In this system, a county can belong to a metropolitan area without itself having 50,000 inhabitants, if it is part of a larger urban agglomeration. A county with a population in excess of 10,000 can be classified as rural if it lacks an urban core.

Differences in the quality of local internet infrastructure are a potential confounder in our empirical specifications. To address this, we use data from the US Federal Communications Commission. ${ }^{6}$ The dataset describes the share of population per county with access to different broadband technologies and speed levels. We calculated a weighted average over technologies and speed levels to obtain the mean broadband speed as an approximation of Internet quality.

As further controls, we collected socio-economic data from the US Census Bureau American Community Survey (US-Census, 2016). For variable selection, we drew on previous studies that analysed the geography of online platforms (Borchert et al., 2018; Graham et al., 2015; Stephany et al., 2019). To characterise the local economy and the local labour market, we used median commuting time in minutes, log-10 number of firms per capita, unemployment rate, and log-10 median household income in USD. Demographics are captured by the log-10 county population size and by a score measuring the educational level of the county's population. We also included indicator variables for rural and micropolitan counties, and for spatial adjacency to a metropolitan area.

\subsection{Determining the online labour skill level}

For the second hypothesis, we need to assess the required skill level of each project transacted through the online labour platform. To achieve this, we map the platform's project categorisation system to the Standard Occupation Classification (SOC) system used by the 
US Bureau of Labour Statistics. We then calculate a numerical score that reflects each project category's estimated required education level, as detailed below. This method is not perfect: it ignores variation in skill requirements between projects in one category, and equates educational qualifications with skills. But the advantaged of the method is that it yields a common measure that provides comparability to the overall education level of a county.

For the mapping, we use the 'SOCcer' tool (Russ et al., 2016), an online application developed by the National Institutes of Health to matche free-text job information to

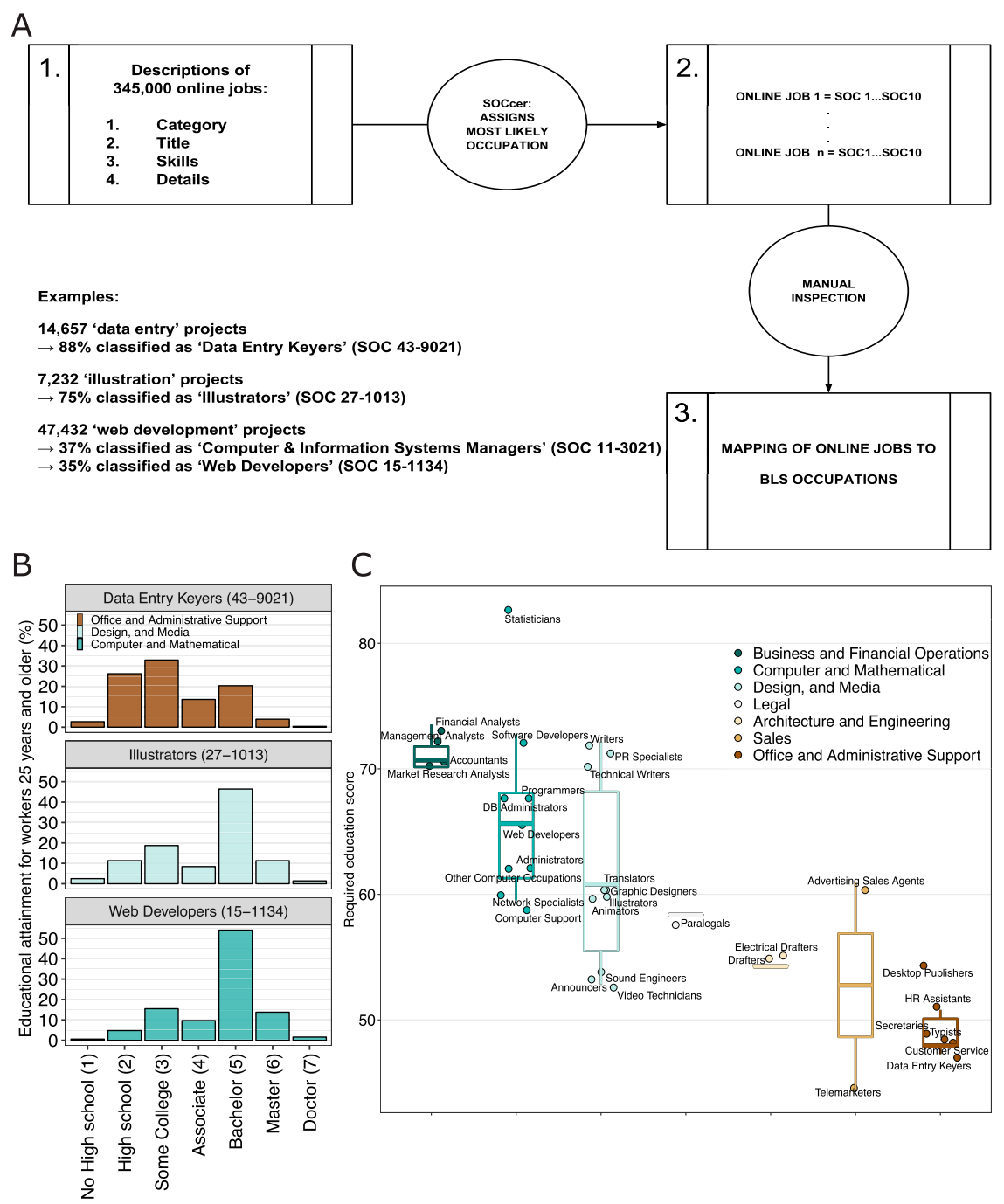

Figure 1. (A) Mapping of online jobs to SOC: 1. the category, title, required skills and details of all online projecs are fed into the SOCcer classifier. 2. The tool yields ten suggested SOC codes per project. 3. The results are manually inspected and matched with the most likely and reasonable SOC occupation. (B) Educational attainment distributions of different occupations, used to calculate a required skill score per occupation $(\mathbf{C})$ Derived required skill scores of all occupations in the dataset, which vary substantially between the categories. 
SOC-2010 occupation codes (Figure 1(A)). As our main transactions dataset does not include free-text project descriptions, we collected a supplementary dataset to perform the mapping. In January 2016, we drew a random sample of 345,000 transactions histories from 46,791 workers using the platform's application programming interface. ${ }^{7}$ This dataset includes each project's category, title, skill requirements (indicated by the employer), and a free-text description (element 1. in Figure 1(A)). Each project is fed into the SOCcer classifier, yielding the 10 most likely SOC codes (element 2.). The most frequently appearing top result within a category was then selected as the category's SOC code. The results for each category were manually inspected to ensure a reasonable matching (element 3.). This was done by comparing the definitions of the most frequently appearing SOC code with a number of project descriptions in the category. ${ }^{8}$ If these did not provide a reasonable match, the next most frequent code was inspected until a reasonable match was found.

For example, the classifier assigned $88 \%$ of 'data entry' projects to 'Data Entry Keyers' (SOC code 43-9021); an obviously good fit. Similarly, it assigned 75\% of the 'illustration' projects to 'Illustrators' (SOC code 27-1013). In contrast, only 37\% of 'web development' projects were assigned to 'Computer and System Managers', while 35\% were classified as 'Web Developers'. This result reflects the variation in the project descriptions and the similarity of the suggested occupations. Web Developers belong to the broader occupational group of '15-0000 Computer and Mathematical Occupations', which is a better fit with the project descriptions than 'Computer and Systems Managers' ('11-0000 Management Occupations'). Accordingly, we selected 'Web Developers' (SOC-code 15-1134) as the code for the 'web development' project category. In total, we mapped all 83 online project categories to 34 SOC occupations.

This mapping allowed us to calculate the estimated required educational level of each project, using the occupation-specific educational attainment statistics from the Bureau of Labour Statistics (Figure 1(B) shows three examples). ${ }^{9}$ To obtain a single numerical score from the distributions, we calculated a weighted average by multiplying the proportion of workers at each educational level by Likert scale values. For example: 3\% of the Data Entry Keyers have no high school diploma (Likert value 1), 26\% have a diploma (2), 33\% have some college education (3), 14\% have an Associate's degree (4), 20\% have a Bachelor's degree (5), $4 \%$ a Master's degree (6), and 1\% a Doctoral degree (7). Accordingly, the overall score of Data Entry Keyers is 48. The scores for Illustrators and Web Deveopers are 60 and 65 , respectively. The resulting score only roughly approximates the educational variety of different occupations, but it yields one common scale to compare the skill levels of different online jobs, which we need to examine $H 2$.

The scores of the 34 occupations vary substantially between the occupational groups (Figure 1(C)). For example, the median score of the group 'Office and Administrative Support' is 48 , while it is 65 for 'Computer and Mathematical'. The mapping also shows that all online jobs correspond with occupations that have been identified as 'outsourcable' (Blinder, 2009): the occupations are defined by tasks that do not require the physical presence at a certain location.

We average the scores of all online projects performed in a county to obtain a measure of the relative online skill level of a county's online workforce. To account for heterogeneity in the educational attainment distribution across counties, we divide the online skill variable by a numerical education score of the county's overall population, which we have 
calculated in the same fashion as the online skill score. This yields a ratio: values larger (smaller) than one imply that the jobs conducted by the online workforce in a county are of higher (lower) educational level than the average educational level of the county's population.

\subsection{Data analysis}

We applied multivariate analyses to investigate both research hypotheses. The number of projects per county $(H 1)$, represents non-normally distributed count data. This requires to apply an appropriate model specification such as the Poisson generalised linear model (GLM), instead of Ordinary Least Squares (OLS). Due to over-dispersion (the variance is much larger than the mean and many counties have no online projects, see the statistically significant estimators of the dispersion parameter $\theta$ in Figure 3), the negative binomial regression, or the zero-inflated negative binomial regression represent even better suited model specifications (Zeileis et al., 2008).

In Figure 3(A), we report the regression results of all four model specifications and present the log Likelihood and the Akaike information criterion as in-sample goodness-of-fit measures. ${ }^{10}$ Additionally, we assess the out-of-sample goodness-of-fit by a ten-fold crossvalidation and by the mean absolute error and the Pearson correlation coefficient $\rho$ between the predicted values and the test data (Figure $3(\mathrm{~A}-\mathrm{C})$ ). The purpose of reporting cross-validated results in this study is to increase the confidence in the research findings by assessing the robustness to outliers, to validate the model choice, and to estimate the prediction accuracy on unseen data (Janeksela, 1982). We report the significance of each parameter estimate in the ten cross-validation regressions on re-sampled data as coloured bars of different length in the 'CV signif. labelled columns (Quattrone et al., 2018). The relative online education/skill score $(H 2)$, is normally distributed (Figure 2(C)). Accordingly, ordinary least squares provides an appropriate model specification.

To test for spatial autocorrelation (spatial error), we report Moran's I measure of spatial autocorrelation (Moran, 1950) and Monte Carlo simulated p-values. ${ }^{11}$

\section{Results}

Substantial urban-rural differences characterise the online labour market in the United States (Figure 2). In line with our theoretical framework, the vast majority of online labour demand is clustered in urban centres. The majority of online labour supply in absolute terms likewise comes from metropolitan counties, but rural areas supply more online labour proportional to their population (Figure 2(A,C)); as hypothesised $(H 1)$.

We also find that, as hypothesised $(\mathrm{H} 2)$, online workers in rural counties supply higherskilled labour compared to online workers in urban counties, relative to the county's average education level (Figure 2(B)). In fact, we find that rural counties supply slightly higherskilled labour than urban counties do even in absolute terms (Figure 2(C)), despite average educational levels being notably higher in urban areas (Figure 2(E)).

Figure 3(A) shows that the differences in online labour supply between rural and metropolitan counties are statistically significant and robust to outliers. Our models indicate positive associations between the number of online projects supplied and the main control variables: population size, county education score, and average broadband 
A

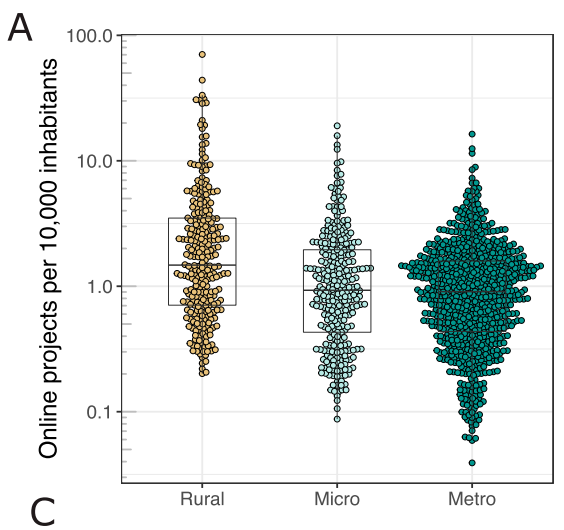

B

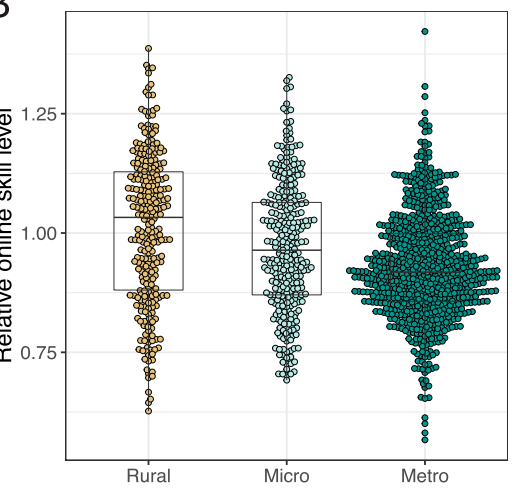

\begin{tabular}{llllll}
\hline & \multicolumn{3}{c}{ Metropolitan } & \multicolumn{3}{c}{ Micropolitan } \\
& Central & Outlying & Central & Outlying & Rural \\
\hline Online Labour (county medians) & & & & & \\
$\quad$ Demand & 50 & 6 & 4 & 0 & 0 \\
$\quad$ Demand per 10,000 inhabitants & 2.53 & 1.17 & 0.72 & 0.00 & 0.00 \\
$\quad$ Supply & 19 & 4 & 4 & 2 & 3 \\
$\quad$ Supply per 10,000 inhabitants & 0.89 & 0.93 & 0.88 & 2.26 & 1.54 \\
\hline Education / skills (county means) & & & & & \\
$\quad$ Online skill level & 64.1 & 65.2 & 64.5 & 63.5 & 65.4 \\
County education level & 69.6 & 65.4 & 65.5 & 62.6 & 62.9 \\
$\quad$ Relative Online skill level & 0.92 & 0.97 & 0.97 & 1.00 & 1.01 \\
\hline Population & & & & & \\
$\quad$ Number of counties & 648 & 180 & 301 & 19 & 286 \\
$\quad$ Median population size (tsd.) & 171 & 50 & 47 & 13 & 20 \\
$\quad$ Average share of urban population (\%) & 80 & 43 & 54 & 17 & 22 \\
\hline Economic factors & & & & & \\
$\quad$ Average unemployment rate (\%) & 9.3 & 9.3 & 9.8 & 9.2 & 9.4 \\
$\quad$ Median commuting time (min.) & 24 & 28 & 21 & 25 & 24 \\
$\quad$ Median household income (tsd. \$) & 51.5 & 50.8 & 42.9 & 42.9 & 40.5 \\
$\quad$ Median number of firms per 10,000 inhabitants & 0.82 & 0.77 & 0.75 & 0.81 & 0.84 \\
\hline
\end{tabular}

$\mathrm{D}$

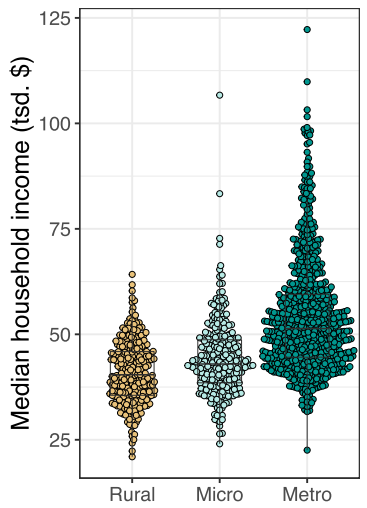

$\mathrm{E}$

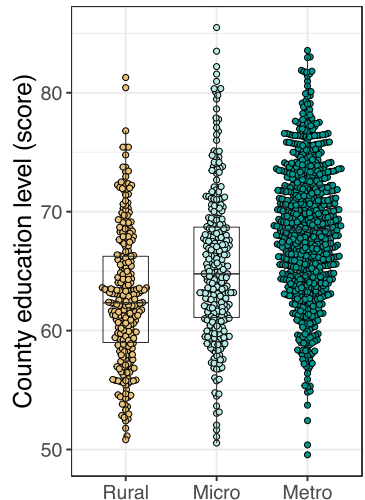

$\mathrm{F}$

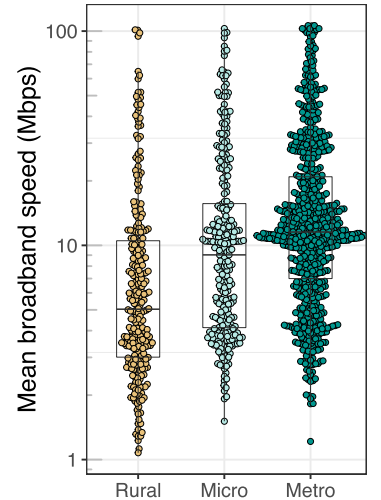

Figure 2. (A-B) Distributions of the number of projects per capita and relative online skill score in metropolitan, micropolitan, and rural counties. Rural counties tend to supply more online labour that is of higher skill level than urban areas. (C) Summary statistics of online labour demand and supply, skill level, population and economic factors in metropolitan, micropolitan, and rural counties. (D-F) Distributions of the number of median household income, county education score, and broadband speed in metropolitan, micropolitan, and rural counties. Rural counties, on average, show lower values than urban areas. 


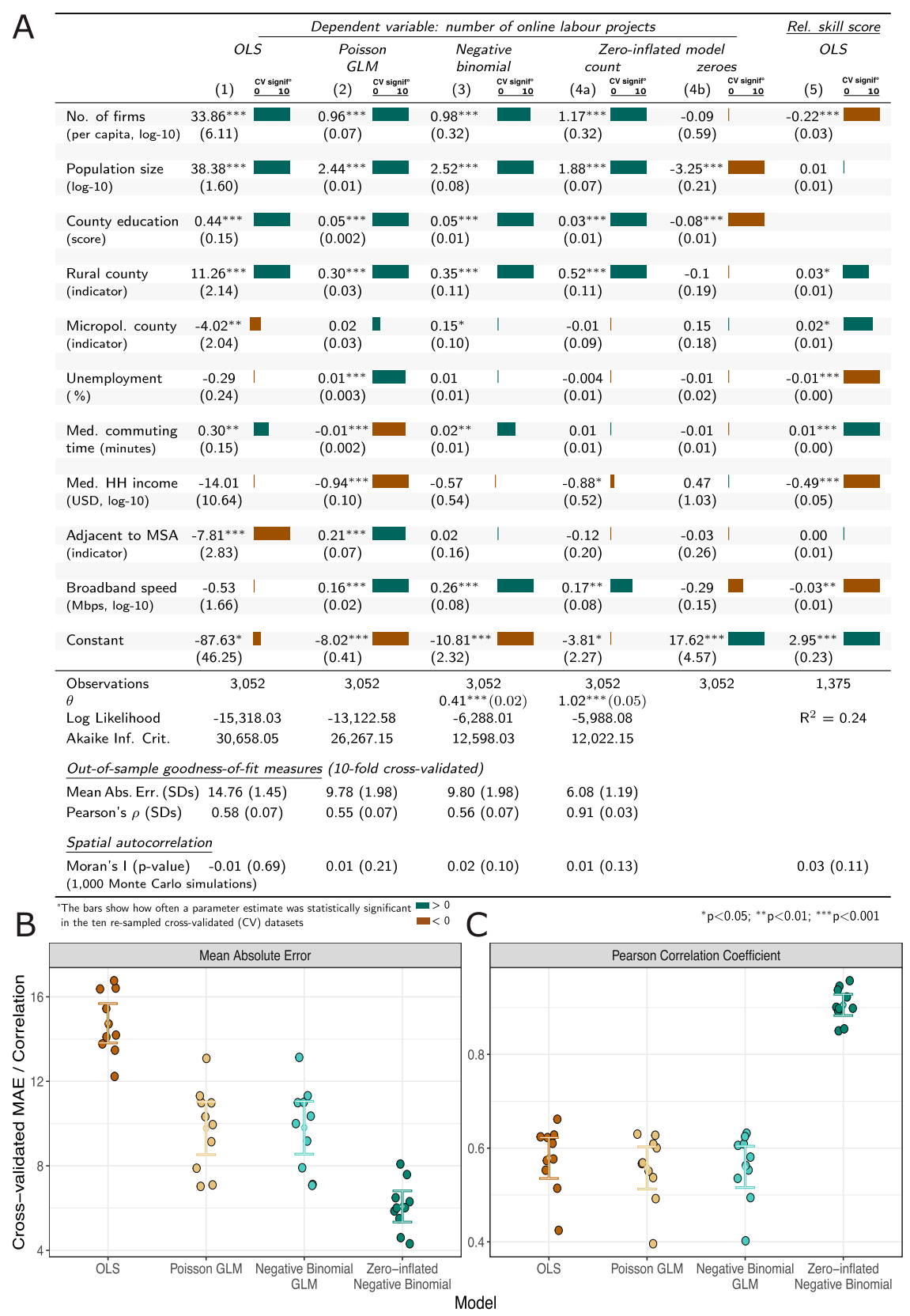

Figure 3. (A) Regression models associating the number of online labour projects and the relative online skill level to regional indicators and socio-economic control variables: rural areas provide significantly more and higher skilled online labour than urban centres. (B-C) Out-of-sample Mean Absolute Error and Pearson Correlation Coefficient: the zero-inflated negative binomial model performs best (dots represent cross-validated prediction results; error bars show mean $\pm 2 \cdot S D$ ).

speed. In other words, counties with larger, better educated populations, and those with better Internet infrastructure tend to provide more online labour. The number of local firms is also positively associated with online labour supply. This could be because the 
variable reflects not only local labour demand but also local labour supply, in terms of working age population, and number of locally incorporated independent contractors.

Even after these controls, ruralness stands out as having an additional positive effect on online labour suppy (fourth row). This finding holds across all model specifications (models 1-4a) and in all cross-validated samples (see the wide green bars). The zero-inflated negative binomial regression provides the best model fit both in term of in-sample goodness-offit (Figure 3(A)), and out-of-sample prediction accuracy (Figure 3(B,C)). The high crossvalidated out-of-sample correlation between the predicted number of projects and the test data of $\rho=0.9$ underlines the good fit of model 4 , which estimates the zero counts explicitly.

To give intuition for the magnitude of the rural county coefficient, we provide a numerical illustration from the non-linear model 4 . Setting all control variables at their medians, a metropolitan county would be estimated to supply 10.0 projects while a rural county would be estimated to supply 16.8 projects. Thus, other things being the same, rural counties are estimated to supply approximately $67 \%$ more online labour projects than metropolitan counties.

Model 5 also shows a positive association between the relative online skill score and the rural county indicator, although the relationship is less pronounced. Counties with lower incomes, longer commuting times, and fewer firms tend to supply higher-skilled labour online, which is in line with the theoretical model. Even after these controls, rural has a positive effect on the skill level. Interestingly, poorer Internet infrastructure is also positively associated with higher-skilled online labour supply, even though higher-skilled work is likely to require better Internet connectivity. This could be because the Internet infrastructure variable reflects the average level of the infrastructure (which is correlated with local opportunities); individual online workers may have connectivity that differs substantially from the average (LaRose et al., 2007).

We also find that only $45 \%$ of all counties and $21 \%$ of the rural counties in the contiguous United States participated in the online labour market at the time the data was collected (Figure 4(A,B)). Participation tends to be geographically clustered: most of the metropolitan areas (dark green) in the densely populated coastal regions supply online labour, while large parts of the rural Midwestern United States do not. ${ }^{12}$ Many of the active rural counties (light green) appear to be adjacent to metropolitan areas. However, the 'Adjacent to Metropolitan Statistical Area (MSA)' indicator variable (Figure 3(A)) is not statistical significant in most of the regression models, and the Monte Carlo simulated Moran's I p-values do not provide evidence that the statistical results are driven by spatial autocorrelation.

Figure $4(\mathrm{C})$ suggests some potential explanations for the geographic disparities in online labour market participation. Overall, the least populated, least urbanised counties are less likely to supply online labour. This corresponds to the negative coefficients of population size and broadband speed in the zero-count model $4 \mathrm{~b}$ (Figure 3(A)). The non-participating counties tend also to have a slightly less educated population (Figure $4(B)$ ). Together with the non-significant 'Rural County' coefficient in model $4 \mathrm{~b}$, these observations indicate that it is not rural counties per se that are less likely to adopt online labour platforms, but rather the least urbanised areas with lowest education levels, which also lack good Internet infrastructure. 
A

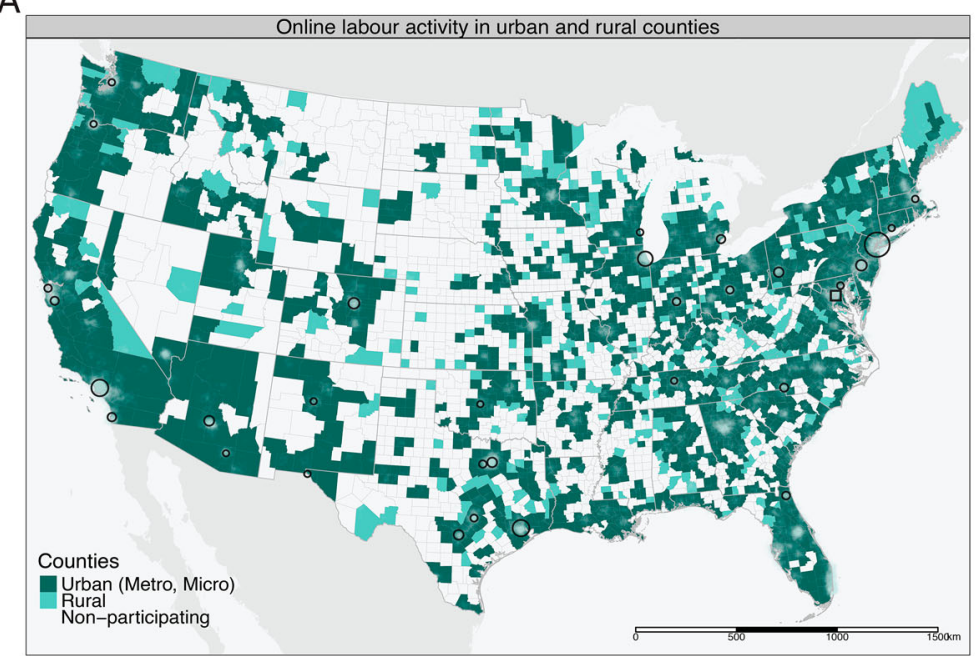

B

\begin{tabular}{|c|c|c|}
\hline Rural online labour market activity & yes & no \\
\hline \multicolumn{3}{|l|}{ Online Labour (county medians) } \\
\hline Demand & 0 & 0 \\
\hline Demand per 10,000 inhabitants & 0 & 0 \\
\hline Supply & 3 & - \\
\hline Supply per 10,000 inhabitants & 1.54 & - \\
\hline \multicolumn{3}{|l|}{ Education / skills (county means) } \\
\hline Online skill level & 65.4 & - \\
\hline County education level & 62.9 & 62.6 \\
\hline Relative Online skill level & 1.01 & - \\
\hline \multicolumn{3}{|l|}{ Population } \\
\hline Number of counties & 286 & 1026 \\
\hline Median population size (tsd.) & 20 & 10 \\
\hline Average share of urban population (\%) & 22 & 21 \\
\hline \multicolumn{3}{|l|}{ Economic factors } \\
\hline Average unemployment rate (\%) & 9.4 & 8.3 \\
\hline Median commuting time (min.) & 24 & 21 \\
\hline Median income (tsd. \$) & 40.5 & 40.6 \\
\hline Median no. of firms per 10,000 inhabitants & 0.84 & 0.85 \\
\hline \multicolumn{3}{|c|}{ Shared boundaries with urban areas (\% of rural counties) } \\
\hline Adjacent to Metropolitan area & 81 & 75 \\
\hline Adjacenct to Metro-/ Micropolitan area & 90 & 86 \\
\hline
\end{tabular}

C

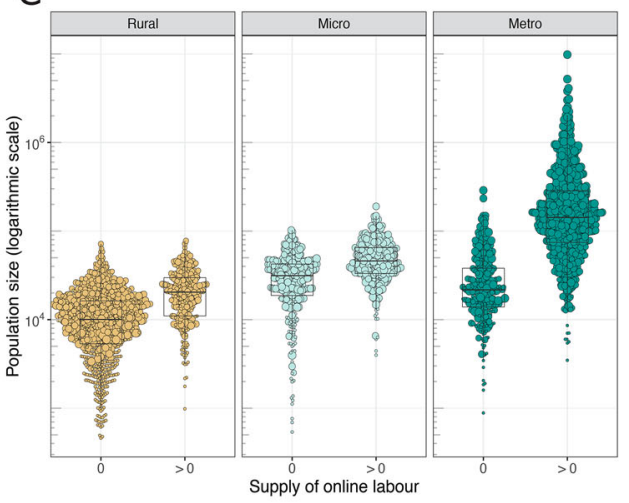

Share of Urban Pop. (\%) $0 \quad 0 \quad 0 \quad 25 \bigcirc 50 \bigcirc 75 \bigcirc 100$

Figure 4. (A) US continental map highlighting urban areas (dark green) and rural counties (light green) supplying online labour, and non-participating counties (white). (B) Summary statistics of participating and non-participating rural counties. (C) Distribution of population size and share of urban population in participating and non-participating metropolitan, micropolitan, and rural counties: independently of the county type, it is the less populated and less urbanised counties that do not participate.

\section{Discussion}

ICTs have long been predicted to make cities as hubs of economic organisation obsolete and spread economic opportunities to rural areas (Cairncross, 1997; Graham, 1998). However, the actual trend in the 21 st century has been the opposite. In the United States, ICT and media industry hubs such as San Francisco, Seattle, and New York continue to attract growing numbers of job-seekers, while deprivation in rural America has deepened (Clark et al., 2018; Glasmeier, 2018). We argued that one explanation for this 'urbanisation paradox' is that enhanced information flows alone are not enough to reorganise the geography of economic activity. In contrast to the 'death of distance' discourse (Cairncross, 1997) 
that predicted diminishing urban advantages due to ICT-enabled information flows, economic sociology and economic history have underlined the importance of 'systems of control' in supporting economic activity (Granovetter, 2005; North, 1990; Ogilvie, 2011). Thus, even though telecommuting and virtual teamwork have been common for some time, actual job seeking and hiring have continued to favour proximate interactions, where local institutions and informal social controls can secure cooperation and establish trust (Granovetter, 1985).

In the empirical part of this article, we observed that in a small but rapidly growing sliver of the ICT economy, the urbanisation trend appears to have been bucked: workers in rural American counties made more use of the online labour market for project-based remote knowledge work than urban Americans did. We argue that this is because digital platforms have started to provide formal and informal cooperation enforcement mechanisms that extend over distance. Although such ICT-mediated reputation systems and remote monitoring technologies bring their own problems (Agrawal et al., 2016; Lehdonvirta et al., 2018; Wood, Lehdonvirta, et al., 2018), they enable work to be contracted and delivered across distance. As a result, the rural Americans in our sample used the platform to obtain work online.

We also found that rural counties supplied, on average, higher-skilled online work than urban areas. This finding held in both relative and absolute terms, and even after accounting for common socio-economic control variables and disparities in Internet infrastructure across US counties. According to our interpretation, this happens because incentives for skilled rural specialists benefit the most from using an online labour platform, as it allows them to access specialised demand beyond their local labour markets and thus benefit from 'virtual agglomeration'. This may have substantial implications for regional development, because the presence and retention of highly skilled workers in a rural community is likely to positively affect the wider local economy as well (Roberts \& Townsend, 2016).

A question that remains open is whether the skilled rural online workers observed in this study were locals or reverse migrants moving from cities to countryside. In what has been termed 'counterurbanisation', studies have documented skilled workers in knowledge-intensive industries escaping urban congestion by moving to rural areas, aiming to enjoy a less stressful lifestyle whilst continuing to employ their skills (Herslund, 2012; Mitchell, 2004; Roberts \& Townsend, 2016). One of the challenges they face is that there may be little local demand for their skills, necessitating frequent and stressful trips back to the city or to the wider region (Herslund, 2012). Internet adoption and the diffusion of practices such as teleworking are thought to alleviate this barrier to counterurbanisation (Roberts \& Townsend, 2016). Along the same lines, online labour platforms, which we conceptualised as consisting of both new technologies and associated practices, could be seen as further enablers, allowing former city professionals to not just maintain existing sources of work but also obtain new work without physically visiting the city. Previous studies suggest that online labour platforms are frequently used by migrants (Pajarinen et al., 2018), but also that they are used by people indigenous to marginalised regions of the world (Wood, Lehdonvirta, et al., 2018). It thus seems likely that the skilled rural online workers observed in this study represent a mix of both rural indigenes and cityborn in-migrants. 
Despite these advantages, only a minority of rural counties participated in the online labour market at the time of data collection. The least populated and least educated counties with the least Internet connectivity were the least likely to participate; these are predominantly agricultural regions. This is concerning, because these regions tend to be most affected by rising spatial inequalities (Glasmeier, 2018; Salemink et al., 2017). Not every county may be home to specialised workers with marketable skills. We found that most of the projects transacted online were related to occupations closely associated with ICTs and other knowledge-intensive industries. Places that are home to such industries and related educational institutions are probably more likely to give rise to skilled online labour workforces (Stephany \& Braesemann, 2017). Alternatively, the places must be able to attract skilled workers from elsewhere. Thus, even with online labour markets there is no complete liberation from the 'tyranny of distance' (Virilio, 1993).

\subsection{Methodological limitations and future research}

This study is the first to investigate urban-rural divides in online labour markets with highly granular geographic and occupation-specific data. The interpretation of the findings is constrained by the available online labour market data. The dataset is sparse and restricted to a six-month time window. Thus, we are limited to reporting correlations, not causal relationships. And although the hypotheses were derived before the analyses were conducted, the design was not pre-registered and the inferences we draw should be considered exploratory.

To minimise uncertainty with respect to unobserved heterogeneity, we have restricted the study's scope to the relatively homogeneous United States, included important local socio-economic control variables and measures of broadband quality, carefully derived the statistical model specification and validated its robustness to outliers. However, some heterogeneity, which cannot be controlled for without time series data, remains in the county-level data, and even more on the project level. Factors with potential effects on the geographic online labour disparities that we could not control for are regulatory differences that make independent contracting more or less desirable in different locations. Some disparities could also reflect differences in awareness of online labour platforms at the time of the study, which remain a relatively new innovation still in the process of diffusion (Kässi \& Lehdonvirta, 2018b). Such market dynamics might affect the evolving geographies in the future.

To test the generalisability of the findings, future work should extend the research on urban-rural divides in online labour market participation to other platforms and to more countries. In particular, longer transactions time-series data would make it possible to investigate spatial diffusion dynamics and the influence of local factors on the adoption likelihood in more detail.

Nevertheless, the study helps to reveal the potential and limitations of online labour as means of regional, in particular rural, development. Such an investigation is especially timely, as development agencies and other organisations have initiated programmes that aim to use online labour platforms to promote economic development in the world's marginalised regions (Suominen, 2017). More generally, the study contributes to the 'place matters' debate by expanding focus from disparities in access and digital literacy to the 
availability of control mechanisms necessary for economic activity. Future research could seek to identify other domains beyond labour markets where new technologies and practices may be offering substitutes to place-bound control mechanisms, thus potentially alleviating urban-rural divides.

\section{Notes}

1. Note that we do not investigate platforms mediating local tasks (such as Uber) or Microwork (such as Amazon Mechanical Turk), but data from an online freelancing platform. Such freelancing platforms coordinate larger projects and tasks that are usually of higher complexity and skill requirements than tasks conducted via Microwork platforms. For more details on the characteristics of the two major forms of online platform work, see Corporaal (2017).

2. In the online setting, reputation via personal recommendations is replaced by the platform reputation system. Therefore, it becomes more independently of persons and places.

3. The relation between urban agglomeration, the concentration of specialised (university) education, and resulting higher wages is an intensively discussed phenomenon in the literature (Adamson et al., 2004; Glaeser et al., 2001; Newbold \& Brown, 2015). When comparing the online labour skill level of rural and urban areas, we correct for this disproportionate concentration of human capital in urban areas, as we divide the online labour skill level of a county by the general education level in the county (more details in the next section).

4. Details in (Lehdonvirta et al., 2018).

5. https://www.census.gov/geo/maps-data/data/cbf/cbf_description.html

6. The data is downloaded from https://opendata.fcc.gov/Wireline/Area-Table-June2016/nb5qgkcn (accessed 2019-06-05).

7. Details in Kässi and Lehdonvirta (2018a).

8. https://www.bls.gov/soc/soc_2010_definitions.pdf

9. https://www.bls.gov/emp/tables/educational-attainment.htm

10. The parameter estimates and standard deviations displayed in the table are calculated from the complete dataset.

11. Moran's I is a correlation-coefficient showing the similarity between neighbouring values (in our case the regression residuals of neighbouring counties). Values close to $+1(-1)$ indicate a clustering of similar (dissimilar) values, while values close to zero indicate that spatial autocorrelation is not prevalent. In order to assess its significance, 1000 Monte Carlos simulations were conducted (Good, 2005). In each simulation the residuals are repeatedly randomised over the counties and Moran's I is recalculated. This yields a distribution of simulated Moran's I values, which we compare to the observed value to obtain a p-value estimate.

12. The small white dots in the map represent the zip-code level centroids of online freelancers: most of them are clustered in the country's largest cities (black circles).

\section{Acknowledgments}

The authors wish to thank the participants of the 'Reshaping Work in the Platform Economy' 2018 conference, whose many helpful comments greatly improved our study, and the two anonymous reviewers whose comments likewise significantly strengthened the manuscript. We moreover wish to express our gratitude to Dr Fabian Stephany for many fruitful conversations during the course of this research.

\section{Disclosure statement}

No potential conflict of interest was reported by the author(s). 


\section{Funding}

This study was supported by a grant from the European Research Council (grant number, 20152020) and by a grant from Google (2018).

\section{Notes on contributors}

Fabian Braesemann is Research Fellow and Data Scientist at the Saïd Business School and Research Associate at the Oxford Internet Institute, University of Oxford. His research focuses on data mining and the statistical analysis of large-scale online data to understand market and information dynamics in a digitally connected world [email: fabian.braesemann@sbs.ox.ac.uk].

Vili Lehdonvirta is an Associate Professor and Senior Research Fellow at the Oxford Internet Institute, University of Oxford, and a Fellow at the Alan Turing Institute. He is an economic sociologist whose research examines how digital technologies are shaping the organisation of economic activities in society.

Otto Kässi is a Research Economist at Etla Economic Research and a Research Associate at the Oxford Internet Institute. His research examines how the developments in automation, communication and artificial intelligence affect firms, workers and economic organisation.

\section{ORCID}

Fabian Braesemann (D) http://orcid.org/0000-0002-7671-1920

Vili Lehdonvirta (D) http://orcid.org/0000-0002-6509-1703

Otto Kässi (iD) http://orcid.org/0000-0002-8666-200X

\section{References}

Adamson, D. W., Clark, D. E., \& Partridge, M. D. (2004). Do urban agglomeration effects and household amenities have a skill bias? Journal of Regional Science, 44(2), 201-224. https://doi. org/10.1111/jors.2004.44.issue-2

Agrawal, A., Lacetera, N., \& Lyons, E. (2016). Does standardized information in online markets disproportionately benefit job applicants from less developed countries? Journal of International Economics, 103, 1-12. https://doi.org/10.1016/j.jinteco.2016.08.003

Baker, P. M., \& Ward, A. C. (2002). Bridging temporal and spatial "gaps": The role of information and communication technologies in defining communities. Information, Communication \& Society, 5, 207-224. https://doi.org/10.1080/13691180210130789

Beerepoot, N., \& Lambregts, B. (2015). Competition in online job marketplaces: Towards a global labour market for outsourcing services? Global Networks, 15(2), 236-255. https://doi.org/10. 1111/glob.2015.15.issue-2

Bettencourt, L. M., Samaniego, H., \& Youn, H. (2014). Professional diversity and the productivity of cities. Scientific Reports, 4, 5393. https://doi.org/10.1038/srep05393

Blinder, A. S. (2009). How many US jobs might be offshorable? World Economics, 10, 41.

Borchert, K., Hirth, M., Kummer, M. E., Laitenberger, U., Slivko, O., \& Viete, S. (2018). Unemployment and online labor (Discussion Paper Number 18-023). ZEW - Centre for European Economic Research.

Cairncross, F. (1997). The death of distance: How the communications revolution will change our lives. Orion Business Books.

Castells-Quintana, D. (2017). Malthus living in a slum: Urban concentration, infrastructure and economic growth. Journal of Urban Economics, 98, 158-173. https://doi.org/10.1016/j.jue.2016. 02.003

Castells, M. (1998). End of millennium, the information age: Economy, society and culture (Vol. III). Blackwell. 
Clark, G. L., Feldman, M. P., Gertler, M. S., \& Wójcik, D. (2018). Economic geography in the twenty-first century. The new Oxford handbook of economic geography (pp. 1-16). Oxford University Press.

Corporaal, G. (2017). Organizing with on-demand freelancers in the platform economy. http:// ilabour.oii.ox.ac.uk/organizing-with-on-demand-freelancers-in-the-platform-economy-part-one/.

Davidson, R., \& Poor, N. (2018). Location, location, location: how digital platforms reinforce the importance of spatial proximity. Information, Communication \& Society, 22(10), 1-15.

Drucker, P. F. (1969). The age of discontinuity. Butterworth-Heinemann.

Flecker, J. (2016). Space, place and global digital work. Springer.

Florida, R., \& Mellander, C. (2018). Talent, skills, and urban economics. The new Oxford handbook of economic geography (pp. 499-518). Oxford University Press.

Forman, C., Goldfarb, A., \& Greenstein, S. (2018). How geography shapes - and is shapey by - the internet. The new Oxford handbook of economic geography (pp. 269-285). Oxford University Press.

Ganong, P., \& Shoag, D. (2017). Why has regional income convergence in the US declined? Journal of Urban Economics, 102, 76-90. https://doi.org/10.1016/j.jue.2017.07.002

Gaspar, J., \& Glaeser, E. L. (1998). Information technology and the future of cities. Journal of Urban Economics, 43(1), 136-156. https://doi.org/10.1006/juec.1996.2031

Ghani, E., Kerr, W. R., \& Stanton, C. (2014). Diasporas and outsourcing: Evidence from oDesk and India. Management Science, 60, 1677-1697. https://doi.org/10.1287/mnsc.2013.1832

Gilbert, M. (2010). Theorizing digital and urban inequalities: Critical geographies of 'race', gender and technological capital. Information, Communication \& Society, 13(7), 1000-1018. https://doi. org/10.1080/1369118X.2010.499954

Glaeser, E., \& Gyourko, J. (2018). The economic implications of housing supply. Journal of Economic Perspectives, 32, 3-30. https://doi.org/10.1257/jep.32.1.3

Glaeser, E. L., \& Kahn, M. E. (2004). Sprawl and urban growth. Handbook of regional and urban economics (Vol. 4, pp. 2481-2527). Elsevier.

Glaeser, E. L., Kolko, J., \& Saiz, A. (2001). Consumer city. Journal of Economic Geography, 1, 27-50. https://doi.org/10.1093/jeg/1.1.27

Glasmeier, A. K. (2018). Income inequality and growing disparity: Spatial patterns of inequality and the case of the USA. The new Oxford handbook of economic geography (pp. 63-77). Oxford University Press.

Good, P. I. (2005). Permutation, parametric, and bootstrap tests of hypotheses. Springer.

Graham, S. (1998). The end of geography or the explosion of place? Conceptualizing space, place and information technology. Progress in Human Geography, 22, 165-185. https://doi.org/10. 1191/030913298671334137

Graham, M., Straumann, R. K., \& Hogan, B. (2015). Digital divisions of labor and informational magnetism: Mapping participation in wikipedia. Annals of the Association of American Geographers, 105(6), 1158-1178. https://doi.org/10.1080/00045608.2015.1072791

Granovetter, M. (1985). Economic action and social structure: The problem of embeddedness. American Journal of Sociology, 91(3), 481-510. https://doi.org/10.1086/228311

Granovetter, M. (2005). The impact of social structure on economic outcomes. Journal of Economic Perspectives, 19, 33-50. https://doi.org/10.1257/0895330053147958

Greenwood, M. J. (1997). Internal migration in developed countries. Handbook of Population and Family Economics, 1, 647-720. https://doi.org/10.1016/S1574-003X(97)80004-9

Hannák, A., Wagner, C., Garcia, D., Mislove, A., Strohmaier, M., \& Wilson, C. (2017). Bias in online freelance marketplaces: Evidence from taskrabbit and fiverr. Proceedings of the 2017 ACM conference on computer supported cooperative work and social computing (pp. 1914-1933). ACM.

Hardy, J., \& Hollinshead, G. (2016). "Clouds" in the desert? Central and Eastern Europe and Ukraine in the new division of labour for business services and software development. Space, place and global digital work (pp. 83-103). Springer.

Hargittai, E. (2002). Second-level digital divide: Differences in people's online skills. First Monday, 7. https://doi.org/10.5210/fm.v7i4.942 
Herslund, L. (2012). The rural creative class: Counterurbanisation and entrepreneurship in the Danish countryside. Sociologia Ruralis, 52(2), 235-255. https://doi.org/10.1111/j.1467-9523. 2011.00560.x

Hong, Y., \& Pavlou, P. (2014). Is the World truly'flat'? Empirical evidence from online labor markets. Horrigan, J. B. (2010). Broadband adoption and use in America (Working Paper Number 1). Federal Communications Commission.

Horton, J. J. (2010). Online labor markets. International workshop on internet and network economics (pp. 515-522). Springer.

Horton, J., Kerr, W. R., \& Stanton, C. (2017). Digital labor markets and global talent flows (Working Paper Number 23398). National Bureau of Economic Research.

Howard, P. N., Busch, L., \& Sheets, P. (2010). Comparing digital divides: Internet access and social inequality in Canada and the United States. Canadian Journal of Communication, 35. https://doi. org/10.22230/cjc.2010v35n1a2192

Ipeirotis, P. G., \& Horton, J. J. (2011). The need for standardization in crowdsourcing. Proceedings of the workshop on crowdsourcing and human computation at CHI, CHI, Vancouver, BC, May 7-12.

Janeksela, G. M. (1982). Increasing confidence in social science research findings via cross-validation. International Review of Modern Sociology, 12(1), 67-75.

Kässi, O., \& Lehdonvirta, V. (2018a). Do digital skill certificates help new workers enter the market? Evidence from an online labour platform (Working Paper). Oxford Internet Institute, University of Oxford. https://osf.io/gejvz/.

Kässi, O., \& Lehdonvirta, V. (2018b). Online labour index: Measuring the online gig economy for policy and research. Technological Forecasting and Social Change, 137, 241-248. https://doi.org/ 10.1016/j.techfore.2018.07.056

Kok, S., \& Weel, B.t. (2014). Cities, tasks, and skills. Journal of Regional Science, 54(5), 856-892. https://doi.org/10.1111/jors.2014.54.issue-5

Kuek, S. C., Paradi-Guilford, C., Fayomi, T., Imaizumi, S., Ipeirotis, P., Pina, P., \& Singh, M. (2015). The global opportunity in online outsourcing (Working Paper Number ACS14228). World Bank Group. http://documents.worldbank.org/curated/en/138371468000900555/The-globalopportunity-in-online-outsourcing.

LaRose, R., Gregg, J. L., Strover, S., Straubhaar, J., \& Carpenter, S. (2007). Closing the rural broadband gap: Promoting adoption of the internet in rural America. Telecommunications Policy, 31 (6-7), 359-373. https://doi.org/10.1016/j.telpol.2007.04.004

Lehdonvirta, V. (2016). Algorithms that divide and unite: Delocalisation, identity and collective action in 'Microwork'. Space, place and global digital work (pp. 53-80). Springer.

Lehdonvirta, V., Kässi, O., Hjorth, I., Barnard, H., \& Graham, M. (2018). The global platform economy: A new offshoring institution enabling emerging economy micro-providers. Journal of Management, 45(2), 567-599.

Lucas, R. E. (2004). Life earnings and rural-urban migration. Journal of Political Economy, 112(S1), S29-S59. https://doi.org/10.1086/379942

Manyika, J., Lund, S., Robinson, K., Valentino, J., \& Dobbs, R. (2015). A labor market that works: Connecting talent with opportunity in the digital age. McKinsey Global Institute. McKinsey \& Company. https://www.mckinsey.com/featured-insights/employment-and-growth/connectingtalent-with-opportunity-in-the-digital-age.

Mayer-Schönberger, V., \& Ramge, T. (2018). Reinventing capitalism in the age of big data. Basic Books.

McLuhan, M. (1964). Understanding media: Extensions of man. Routledge and Kegan Paul.

Mitchell, C. J. (2004). Making sense of counterurbanization. Journal of Rural Studies, 20, 15-34. https://doi.org/10.1016/S0743-0167(03)00031-7

Mollick, E. (2014). The dynamics of crowdfunding: An exploratory study. Journal of Business Venturing, 29, 1-16. https://doi.org/10.1016/j.jbusvent.2013.06.005

Moran, P. A. (1950). Notes on continuous stochastic phenomena. Biometrika, 37, 17-23. https:// doi.org/10.1093/biomet/37.1-2.17

Morgan, N., \& Smit, E. (1996). Contemporary issues in strategic management. Kagiso. 
Negroponte, N. (1995). Being digital. Knopf.

Newbold, K. B., \& Brown, W. M. (2015). The urban-rural gap in university attendance: Determinants of university participation among Canadian youth. Journal of Regional Science, 55(4), 585-608. https://doi.org/10.1111/jors.2015.55.issue-4

North, D. C. (1990). A transaction cost theory of politics. Journal of Theoretical Politics, 2, 355-367. https://doi.org/10.1177/0951692890002004001

Ogilvie, S. (2011). Institutions and European trade: Merchant guilds, 1000-1800. Cambridge University Press.

Pajarinen, M., Rouvinen, P., Claussen, J., Hakanen, J., Kovalainen, A., Kretschmer, T., Poutanen, S., Seifried, M., \& Seppänen, L. (2018). Upworkers in Finland: Survey results (Tech. Rep.). The Research Institute of the Finnish Economy.

Pallais, A. (2014). Inefficient hiring in entry-level labor markets. American Economic Review, 104, 3565-3599. https://doi.org/10.1257/aer.104.11.3565

Pallais, A., \& Sands, E. G. (2016). Why the referential treatment? Evidence from field experiments on referrals. Journal of Political Economy, 124, 1793-1828. https://doi.org/10.1086/688850

Pascal, A. (1987). The vanishing city. Urban Studies, 24, 597-603. https://doi.org/10.1080/ 00420988720080821

Pawley, M. (1995). Architecture, urbanism and the new media. Mimeo.

Pelletier, A., \& Thomas, C. (2018). Information in online labour markets. Oxford Review of Economic Policy, 34(3), 376-392. https://doi.org/10.1093/oxrep/gry005

Philip, L., \& Williams, F. (2018). Remote rural home based businesses and digital inequalities: Understanding needs and expectations in a digitally underserved community. Journal of Rural Studies, 68, 306-318.

Poon, S., \& Jevons, C. (1997). Internet-enabled international marketing: A small business network perspective. Journal of Marketing Management, 13, 29-41. https://doi.org/10.1080/0267257X. 1997.9964457

Quattrone, G., Greatorex, A., Quercia, D., Capra, L., \& Musolesi, M. (2018). Analyzing and predicting the spatial penetration of Airbnb in US cities. EPJ Data Science, 7, 31. https://doi.org/10.1140/ epjds/s13688-018-0156-6

Quigley, J. M. (1998). Urban diversity and economic growth. Journal of Economic Perspectives, 12, 127-138. https://doi.org/10.1257/jep.12.2.127

Riddlesden, D., \& Singleton, A. D. (2014). Broadband speed equity: A new digital divide? Applied Geography, 52, 25-33. https://doi.org/10.1016/j.apgeog.2014.04.008

Roberts, E., \& Townsend, L. (2016). The contribution of the creative economy to the resilience of rural communities: Exploring cultural and digital capital. Sociologia Ruralis, 56, 197-219. https:// doi.org/10.1111/soru.2016.56.issue-2

Russ, D. E, Ho, K.-Y., Colt, J. S., Armenti, K. R., Baris, D., Chow, W.-H., Davis, F., Johnson, A., Purdue, M. P., Karagas, M. R., Schwartz, K., Schwenn, M., Silverman, D. T., Johnson, C. A., \& Friesen, M. C. (2016). Computer-based coding of free-text job descriptions to efficiently identify occupations in epidemiological studies. Occupational and Environmental Medicine, 73(6), 417424. https://doi.org/10.1136/oemed-2015-103152

Salemink, K., Strijker, D., \& Bosworth, G. (2017). Rural development in the digital age: A systematic literature review on unequal ICT availability, adoption, and use in rural areas. Journal of Rural Studies, 54, 360-371. https://doi.org/10.1016/j.jrurstud.2015.09.001

Sawhney, H. (1996). Information superhighway: Metaphors as midwives. Media, Culture \& Society, 18, 291-314. https://doi.org/10.1177/016344396018002007

Shevchuk, A., \& Strebkov, D. (2018). Safeguards against opportunism in freelance contracting on the internet. British Journal of Industrial Relations, 56, 342-369. https://doi.org/10.1111/bjir. 2018.56.issue- 2

Stephany, F., \& Braesemann, F. (2017). An exploration of wikipedia data as a measure of regional knowledge distribution. In G. L. Ciampaglia, A. Mashhadi, \& T. Yasseri (Eds.), Social informatics (pp. 31-40). Springer International Publishing.

Stephany, F., Braesemann, F., \& Graham, M. (2019). Coding together-coding alone: The role of trust in collaborative programming (Tech. Rep.). https://doi.org/10.31235/osf.io/8rf2h. 
Stern, M. J., Adams, A. E., \& Elsasser, S. (2009). Digital inequality and place: The effects of technological diffusion on internet proficiency and usage across rural, suburban, and urban counties. Sociological Inquiry, 79, 391-417. https://doi.org/10.1111/soin.2009.79.issue-4

Strover, S. (2014). The US digital divide: A call for a new philosophy. Critical Studies in Media Communication, 31, 114-122. https://doi.org/10.1080/15295036.2014.922207

Suominen, K. (2017). Fuelling trade in the digital era (Issue Paper). International Centre for Trade and Sustainable Development.

Sveikauskas, L. (1975). The productivity of cities. The Quarterly Journal of Economics, 89(3), 393413. https://doi.org/10.2307/1885259

UN (2018). World urbanization prospects: The 2018 revision (Tech. Rep.). United Nations Department of Economic and Social Affairs. Population Division.

US-Census (2016). 2012-2016 American community survey 5-year estimates. https://factfinder. census.gov/faces/nav/jsf/pages/index.xhtml.

Verboord, M., \& Noord, S.v. (2016). The online place of popular music: Exploring the impact of geography and social media on pop artists' mainstream media attention. Popular Communication, 14(2), 59-72. https://doi.org/10.1080/15405702.2015.1019073

Virilio, P. (1993). The third interval: A critical transition. Rethinking technologies (pp. 3-10). University of Minnesota Press.

Webber, M. M. (1968). The post-city age. Daedalus, 97(4), 1091-1110.

Wood, A. J., Graham, M., Lehdonvirta, V., \& Hjorth, I. (2018). Good gig, bad gig: Autonomy and algorithmic control in the global gig economy. Work, Employment and Society.

Wood, A. J., Lehdonvirta, V., \& Graham, M. (2018). Workers of the internet unite? Online freelancer organisation among remote gig economy workers in six Asian and African countries. New Technology, Work and Employment, 33(2), 95-112. https://doi.org/10.1111/ntwe.12112

Zeileis, A., Kleiber, C., \& Jackman, S. (2008). Regression models for count data in R. Journal of Statistical Software, 27, 1-25. 